\title{
Biopolymers and supramolecular polymers as biomaterials for biomedical applications
}

\author{
Ronit Freeman, Job Boekhoven, Matthew B. Dickerson, \\ Rajesh R. Naik, and Samuel I. Stupp
}

\begin{abstract}
Protein- and peptide-based structural biopolymers are abundant building blocks of biological systems. Either in their natural forms, such as collagen, silk, and fibronectin, or as related synthetic materials, they can be used in various technologies. An emerging area is that of biomimetic materials inspired by protein-based biopolymers, which are made up of small molecules rather than macromolecules and can therefore be described as supramolecular polymers. These materials are very useful in biomedical applications because of their ability to imitate the extracellular matrix in both architecture and the capacity to signal cells. This article describes important features of the natural extracellular matrix and highlights how these features are being incorporated into biomaterials composed of biopolymers and supramolecular polymers. We particularly focus on the structures, properties, and functions of collagen, fibronectin, and silk, and the supramolecular polymers inspired by them as biomaterials for regenerative medicine.
\end{abstract}

\section{Introduction}

The extracellular matrix (ECM) is present within all tissues and organs; it provides mechanical support and both guides and directs cell function. ${ }^{1}$ The ECM is composed of two main classes of macromolecules: proteoglycans and fibrous proteins, with distinct hierarchical assemblies at various length scales., ${ }^{2,3}$ The hierarchical structure-function relationship of these biopolymers regulates the functions of cells, tissues, and organs.

In the context of biomaterials for regenerative medicine, proteins that can be used to construct scaffolds that mimic the structure and function of the ECM are of particular interest. ${ }^{4}$ Specifically, fibrillar proteins that are abundant components of the native ECM, such as collagen and fibronectin (FN), are natural choices for tissue engineering applications..$^{5-7}$ Collagen is responsible for the structural support and elasticity of tissues. ${ }^{8}$ FN supports cell adhesion to the ECM, as well as cell migration, proliferation, and differentiation..$^{9,10}$ In addition to collagen and FN, silk proteins (originating from silkworms and spiders) have attracted considerable interest for tissue engineering applications because of their tailorable mechanical properties, good biocompatibility, and facile processability. ${ }^{11-13}$ Critical to the function of these and other protein biopolymers is their ability to spontaneously assemble from smaller subunits into long uniform structures stabilized by many noncovalent interactions. In some cases, the dynamic features of these interactions are coupled with the capacity of the resulting fibrillar structures to rapidly polymerize and depolymerize and guide specific function through biomechanical and biochemical signals. ${ }^{14-16}$ The intracellular fibers known collectively as the cell's cytoskeleton are the best example of the central functional role of highly dynamic fibrous structures.

The hierarchical self-assembly of proteins into well-defined structures has inspired research on artificial supramolecular architectures intended to mimic the function of native proteins. In these supramolecular assemblies, the monomeric units are held together by multiple noncovalent intermolecular interactions such as hydrogen bonding, ${ }^{17-20}$ metal-ligand coordination, ${ }^{21-23}$ $\pi-\pi$ stacking, ${ }^{24}$ hydrophobic interactions, ${ }^{25}$ and host-guest interactions. ${ }^{26,27}$ Unlike covalent polymerization, all of these processes are highly reversible and dynamic, thus endowing the new polymer materials with many attractive properties. Such properties include a structurally responsive nature, easy synthesis and functionalization, and the possibility of incorporating an array of different ligands through co-assembly of

Ronit Freeman, Simpson Querrey Institute of BioNanotechnology, Northwestern University, USA; ronitfree@gmail.com

Job Boekhoven, Institute for Advanced Study and Chemistry Department, Technische Universität Munchen, Germany; job.boekhoven@ch.tum.de

Matthew B. Dickerson, Materials and Manufacturing Directorate, Air Force Research Laboratory, USA; matthew.dickerson.6@us.af.mil

Rajesh R. Naik, 711th Human Performance Wing, Wright-Patterson AFB OH, USA; rajesh.naik@us.af.mil

Samuel I. Stupp, Simpson Querrey Institute for BioNanotechnology, and Departments of Materials Science and Engineering, Chemistry, Medicine, and Biomedical Engineering, Northwestern University,

USA; s-stupp@northwestern.edu

DOI: $10.1557 / \mathrm{mrs} .2015 .270$ 
the building blocks. ${ }^{28}$ Although a variety of building blocks have been employed to design bioinspired polymeric architectures, ${ }^{29,30}$ peptide-based supramolecular polymers are the most common. Peptide building blocks are ideal mainly because they are the primary signaling components in the ECM. Also, the peptide sequences are biocompatible and degradable and can be quickly and reliably synthesized.

In this article, we discuss the common structural features of the biopolymers collagen, FN, and silk and how their characteristics have inspired the synthesis of peptide-based supramolecular polymers as bioactive materials with tailored properties and customizable functions. We describe the use of these two classes of polymers for regenerative medicine and biomedical applications and address the remaining challenges for the design of future biomaterials for clinical applications.

\section{Structure and organization of protein biopolymers}

Nature provides many examples of structurally complex and functional architectures obtained by integrating multiple simple interactions that act in concert to produce the final macromolecular compound. Proteins are an example of this design strategy. The base level of protein structure is the primary structure, a sequence of amino acid residues covalently linked together to form the linear backbone of the biomolecule. Although the arrangement of amino acid residues might seem rather simple, the primary structure prescribes the folding and higher-order conformation of the protein. The secondary structure describes the local conformation of the protein backbone. The hydrogen bonding of the peptide backbone can result in regular folding patterns such as $\alpha$ helices and $\beta$ sheets. The folding of these peptide chains into tertiary structures is largely determined by hydrophobic interactions and contributions from disulfide bonds. Some proteins are assembled from multiple polypeptide chains; the specific arrangement of these subunits into a multimeric molecule is defined as the quaternary structure of the protein (Figure 1, left). Taken separately, interactions such as hydrogen-bonding and hydrophobic interactions seem rather limited, yet when combined, they contribute to hierarchical self-assembly resulting in an impressive number of uniquely functional proteins. ${ }^{34}$ This hierarchical assembly process is directly responsible for the mechanical properties and bioactivity of protein biopolymers.

One of the most researched families of protein biopolymers is that of collagen, the main component of the ECM, which provides strength and elasticity to tissues, blood vessels, ligaments, and bone. ${ }^{35}$ Collagen Type I, the most abundant collagen in the human body, supports and stabilizes the ECM as a whole, provides attachment sites for adhesion proteins and glycosaminoglycans, and interacts with the cytoskeleton to maintain dynamic exchange between the cell and the matrix. Collagen Type I consists of three polypeptides, so-called $\alpha$ chains with the repetitive sequence Gly-X-Y (called the GXY motif), where X and Y can be any amino acid, including glycine (Gly), proline (Pro), or hydroxyproline (Hyp). The three alpha chains assemble into a triple helix tertiary structure (Figure 1, left). The triple helices themselves assemble further into fibrils stabilized primarily by hydrogen bonding. ${ }^{8,31,32}$ On the next hierarchical level, these fibrils assemble into supramolecular complexes, where different tissues or organs contain fibrils of different diameters. ${ }^{36}$ In the cornea, for example, 20-nm-diameter collagen fibrils are arranged orthogonally to maintain its structure while retaining optical transparency. ${ }^{36}$ In mature tendons, largerdiameter (500-nm) fibrils align in parallel bundles to support the high tensile demands. ${ }^{17}$ Thus, the repetitive primary structure of collagen, its coordinated self-assembly, and the

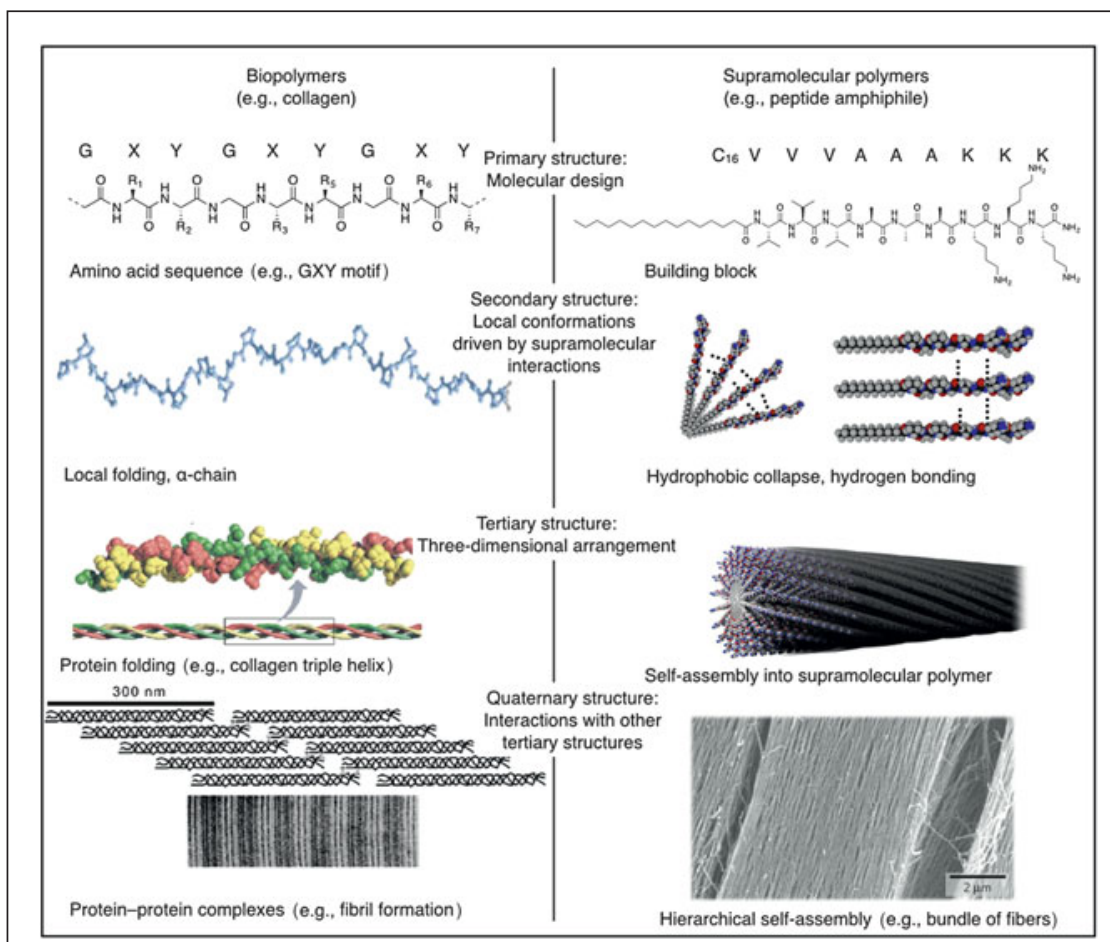

Figure 1. Hierarchical self-assembly of (left) biopolymers and (right) supramolecular polymers. Both biopolymer folding and supramolecular polymer assembly start with a molecular design, coding for organization on several hierarchical levels. In the primary structure of collagen on the left, $G$ represents glycine, and $X$ and $Y$ can be any amino acid, including glycine, proline, or hydroxyproline. In the primary structure of the peptide amphiphile on the right, $\mathrm{A}, \mathrm{K}$, and $\mathrm{V}$ represent the amino acids alanine, lysine, and valine, respectively. Second, the structures order based on local interactions with monomers: neighboring amino acids in the case of biopolymers or adjacent building blocks for supramolecular polymers. On a third level, the monomers act to form a three-dimensional structure such as a fibrillar protein or a supramolecular polymer. Finally, the fibrillar proteins can be organized with other proteins into a functional system. Similarly, self-assembled structures can be assembled hierarchically to form a superstructure. Portions of this figure were reproduced with permission from (left) Reference 31 (@ 2008 Elsevier) and Reference 32 (๑ 2007 Springer) and (right) Reference 33 (๑ 2010 Nature Publishing Group). 
demands from its local microenvironment give rise to its ultimate biological function.

Another ECM protein, FN, is structurally and functionally different from collagen but exploits similar design principles to form fibrils. The FN primary structure contains three repeating $\beta$-sheet structures, designated I, II, and III. ${ }^{37-41}$ Two FN polypeptides associate into a dimer linked by disulfide bonds. This association creates a series of paired ligand-binding domains, spaced at strategic points, with a high affinity for cell membrane receptors, including integrins, and various other ECM components and factors (e.g., heparin sulfate, collagen, ${ }^{42}$ and fibrin). By binding collagen, FN stabilizes its overall scaffold structure, and by linking integrins, FN participates in the cell-matrix crosstalk that controls cell proliferation, migration, and differentiation. When FN recruits other globular molecules from the extracellular space, it initiates polymerization through noncovalent bonding at its $\mathrm{N}$ terminus. ${ }^{43}$ Fibrillar FN is not static. Once it is coupled to cells, it can be rearranged, remodeled, and recycled to meet the demands of its local microenvironment. ${ }^{44}$ A key feature of FN assembly into fibers is the molecule's ability to undergo reversible conformational changes that convert soluble FN from its initial inactivated, compact conformation into a surface-activated, extended conformation.

Silks are a diverse class of protein biopolymers that are produced for use outside the physical environment of the organism and exhibit structure-dependent functional properties. ${ }^{45}$ The silk proteins most extensively studied for regen- nonrepetitive terminal domains ${ }^{52}$ (Figure $2 \mathrm{~b}$ ). The overall structure of the central core of these spidroins is reminiscent of the semicrystalline block copolymer organization of $B$. mori silk, but there are differences between the two materials. Spidroins contain sequence motifs that fold into less-ordered helical and $\beta$-spiral confirmations that contribute to the extensibility and, thus, toughness of the protein fiber. ${ }^{53}$ Polyalanine blocks form crystalline $\beta$-sheet structures that serve as strong intermolecular cross-links, and the crystalline content and crystallite size correlate with the strength of the silk fiber. ${ }^{54}$ Nonrepetitive $\mathrm{N}$ - and C-terminal domains have a globular structure and play a critical role in the storage of the proteins and the assembly of fibers during spinning. ${ }^{11}$ Significant advances in the recombinant production of spidroin-inspired proteins have facilitated the generation of designer silk-like proteins for biomedical research. ${ }^{55,56}$

Although the structures of collagen, FN, and silk proteins are distinct, each biopolymer contains repetitive sequences and domains stabilized by noncovalent bonds that contribute to the bulk mechanical properties of the fibers or networks they form. These properties enable proteins to assemble into hierarchical structures with functions that depend on their ordered arrangements. Their abilities to self-assemble in defined ways, respond to specific environmental stimuli, and adapt to mechanical loads have inspired the development of supramolecular polymers that mimic core "design principles" of structural proteins for a variety of applications. erative medicine include materials naturally produced by spiders and silkworms, as well as engineered proteins whose sequences were inspired by such native silks ${ }^{46-48}$ (Figure 2). The major structural protein of silkworm (Bombyx mori) silk is fibroin, an amphiphilic block copolymer with alternating repetitive hydrophobic and hydrophilic domains. ${ }^{49}$ During fiber spinning, fibroin proteins assemble into semicrystalline structures composed of $\beta$-sheet crystallites and less-structured (or amorphous) regions..$^{50}$ Fibroins are spun by the silkworm into fibers of $\sim 10-25-\mu \mathrm{m}$ diameter $^{51}$ (Figure 2a). These fibroin-based fibers are coated and cemented together by a second family of gluelike proteins called sericins to produce a cocoon that provides a protective environment for the silkworm to undergo its metamorphosis into a moth. Purification of stable aqueous fibroin solutions from these cocoons is straightforward and allows for the generation of regenerated fibroin materials in a variety of forms, including films, fibers, and foams. ${ }^{51}$

The silk dragline fiber produced by spiders contains several high-molecular-weight proteins (spidroins) that are organized in three domains: a large central repetitive core and two

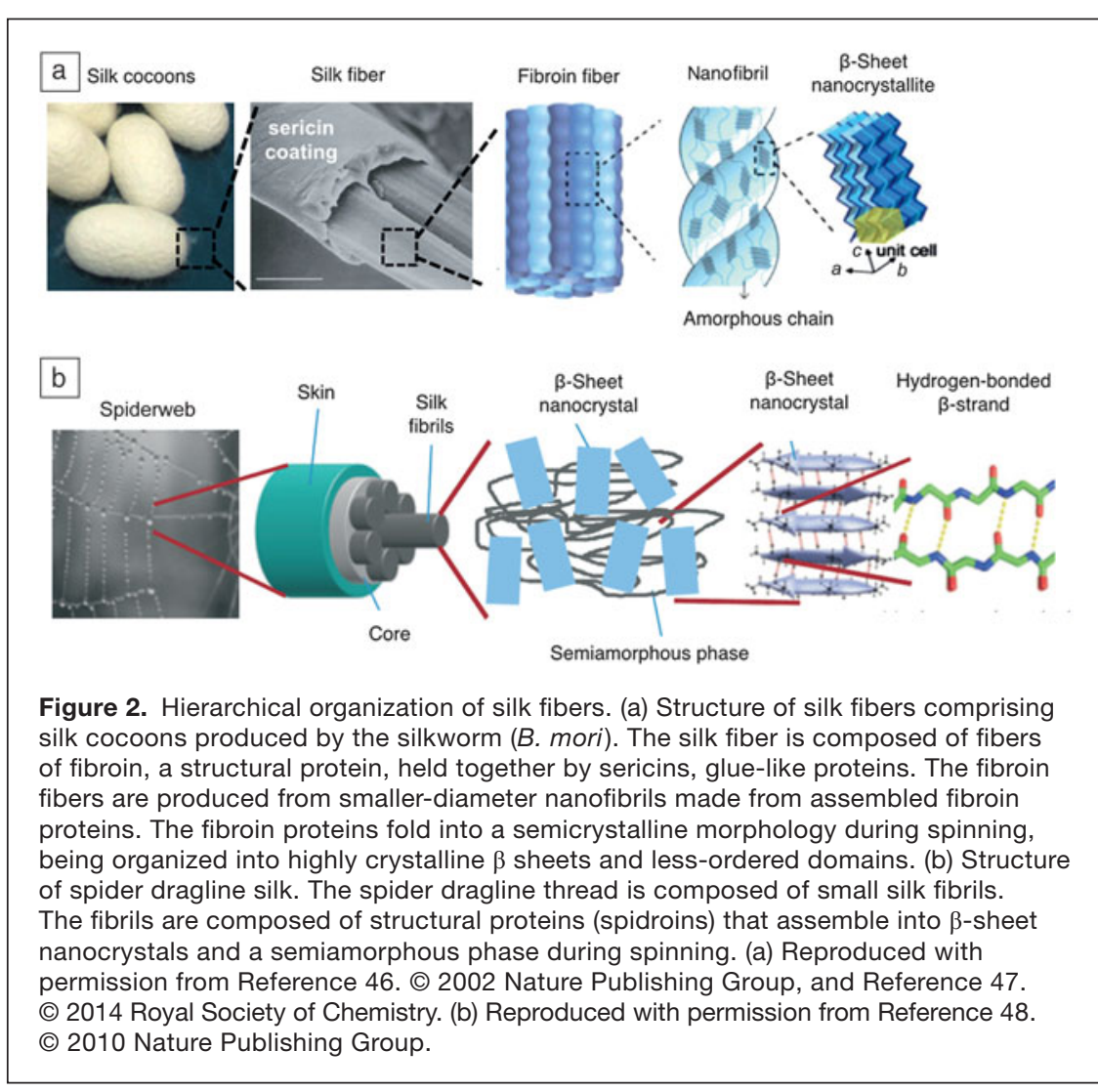




\section{Bioinspired supramolecular polymers: Structure and assembly}

The hierarchical organization of proteins remains an ongoing inspiration for scientists seeking new methods for obtaining elaborate molecular assemblies. Supramolecular polymerization, which exploits noncovalent interactions including hydrogenbonding and $\pi-\pi$ interactions ${ }^{57}$ to direct the self-assembly of molecular units, is a powerful approach to constructing such assemblies. The noncovalent interactions make this class of polymers unique, as they allow the rapid transformation of the material by (locally) breaking and re-forming the noncovalent bonds between monomers. Moreover, the materials can be molecularly engineered to achieve specific features such as biodegradability or bioactivity. As for biopolymers, the organization of supramolecular polymers starts with a molecular design that encodes the properties of the final assemblies (Figure 1, right). The noncovalent bonds between neighboring monomers result in the formation of a stable nucleus. The nuclei grow further to form an ensemble of many molecules, through the process of self-assembly, resulting in polymer growth. On the next hierarchical level, these polymers can interact with one another to form higher-order hierarchical assemblies. As for proteins, although the local interactions between the basic subunits are often simple, these interactions lead to complex architectures over various length scales.

Supramolecular polymers can be divided into two major classes: random-coil and ordered. ${ }^{58}$ The first class is reminiscent of an unfolded protein but formed by noncovalent interactions. Meijer and co-workers studied random-coil supramolecular polymers, yielding an interesting class of materials with properties similar to those of regular polymers but with the dynamics of supramolecular assemblies. ${ }^{59}$ The second class involves the formation of one-dimensional nanoarchitectures with a high degree of internal order (ordered supramolecular polymers) and was developed and extensively studied in the laboratories of Stupp, ${ }^{60-63}$ Aida, ${ }^{64}$ and others. $.55,66$ Ordered supramolecular polymers all share a common feature: The self-assembly of the monomers is driven by at least one type of anisotropic interaction, typically hydrogenbonding or $\pi-\pi$ interactions. These anisotropic interactions are the driving force to form one-dimensional structures, thereby creating polymer-like assemblies. The design of peptidebased ordered supramolecular polymers relies mainly on using conserved amino acid sequences that retain many of the molecular characteristics of the native protein ${ }^{67}$ or using peptide sequences that adopt secondary structures, such as the $\beta$-sheet. ${ }^{68}$

The use of protein-derived peptides enables the structural properties of the native protein to be mimicked using shorter peptide sequences. For example, collagen-mimetic peptides that contain the triad amino acid repeats Gly-Hyp-X and Gly-X-Hyp (where X is usually Pro) ${ }^{69}$ were employed to elucidate the triple-helix structure and the stabilization effects of different amino acid residues ${ }^{70}$ as in native collagen. Hartgerink and co-workers designed and synthesized self-assembling peptides that form collagen-like triple helices with sticky overhangs that direct their assembly into longer fibers and eventually self-supporting hydrogels, recapitulating the hierarchical self-assembly of natural collagen. ${ }^{67}$ In addition to collagen-mimetic peptides, silk-mimetic peptides bearing the morphological features of the natural protein have been synthesized and used to study its secondary structural propensities and folding into an elongated confirmation. ${ }^{71}$

A different category of ordered supramolecular polymers includes short peptide sequences whose self-assembly is driven by electrostatic interactions and $\beta$-sheet formation. ${ }^{72}$ For instance, the RADA16 motif, a 16-fold repetition of the four amino acid residues arginine (R), alanine (A), aspartic acid (D), and alanine (A), has an alternating cationic-hydrophobicanionic-hydrophobic peptide sequence. ${ }^{73-75}$ Complexation of the opposing charges allows the formation of strong $\beta$ sheets, resulting in the formation of ordered supramolecular polymers (Figure 3a). These fibers are able to entangle and form hydrogels under physiological conditions, rendering them useful in the context of regenerative medicine. ${ }^{77}$ In addition to RADA16

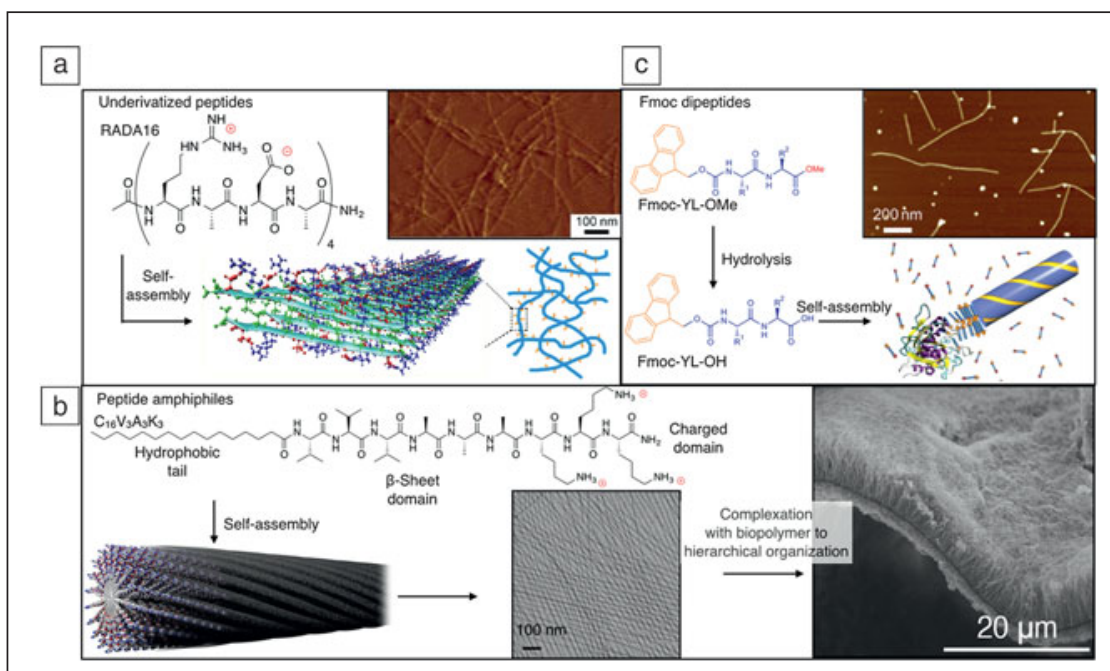

Figure 3. Self-assembly of supramolecular polymers. (a) Molecular design of RADA16. The alternating cationic-hydrophobic-anionic-hydrophobic sequence forces assembly into ribbons, as evidenced by atomic force microscopy (AFM) (inset). (b) Molecular design of peptide amphiphiles (PAs). A hydrophobic tail and $\beta$-sheet domain drive selfassembly into supramolecular polymers. The charged domain ensures solubility of the fibers. PA supramolecular polymers can be complexed with an anionic biopolymer to form hierarchically organized constructs. (c) Molecular design of Fmoc-YL-OMe and Fmoc-YL-OH, where Fmoc is the $N$-(fluorenyl-9-methoxycarbonyl) protecting group, $\mathrm{Y}$ is the amino acid tyrosine (Tyr), and $\mathrm{L}$ is the amino acid leucine (Leu). The hydrophobic Fmoc group and uncharged peptide render Fmoc-YL-OMe insoluble in water. Only upon hydrolysis to Fmoc-YL-OH is the charge balance favorable for assembly into fibers, as evidenced by AFM (inset). (a) Reproduced with permission from Reference 74. (C) 2013 American Chemical Society, and Reference 75. ( 2007 PloS One. (b) Reproduced with permission from Reference 63. () 2013 Royal Society of Chemistry. (c) Reproduced with permission from Reference 76. (c) 2010 Nature Publishing Group. 
and collagen-mimetic peptides, many other underivatized selfassembling peptides exist and have been discussed in various reviews. ${ }^{78}$

Stupp and co-workers developed a prominent example of ordered supramolecular polymers. Adding a hydrophobic tail to one end of a peptide sequence resulted in the formation of a peptide amphiphile (PA) (Figure 3b). ${ }^{60-63}$ The hydrophobic tail renders the peptide insoluble in water, and, as a result, the monomers aggregate upon dispersion in aqueous solutions. Two domains in the peptide sequence prevent the aggregates from forming amorphous precipitates. The first domain consists of amino acids with a high $\beta$-sheet-forming propensity and is directly attached to the hydrophobic tail. These anisotropic interactions ensure that the molecules assemble into supramolecular polymers. ${ }^{79}$ The second domain contains charged amino acids and is attached to the $\beta$-sheet-forming domain. These charges render the fibers water-soluble. A fourth peptide domain can be attached to the charged domain to give the fiber functionality, such as a cell-binding domain ${ }^{80}$ or a catalytically active domain. ${ }^{81}$

Another example of functionalizing peptide sequences to drive self-assembly involves the addition of hydrophobic aromatic domains, such as the $N$-(fluorenyl-9-methoxycarbonyl) (Fmoc) protecting group. This hydrophobic group can drive the self-assembly of extremely short peptide sequences ${ }^{82}$ to form fibers. ${ }^{83}$ The addition of Fmoc dramatically decreases the concentration needed to form supramolecular polymers or hydrogels, ${ }^{84}$ making it more suitable as a biomaterial. In addition, the use of non-natural amino acid sequences allows for the creation of materials with functionalities that are not natively available in biology. For instance, Hirst et al. coupled the self-assembly of Fmoc-Tyr-Leu (where Tyr is tyrosine and Leu is leucine) to the hydrolytic activity of subtilisin (Figure 3c). ${ }^{76}$ This enzyme can hydrolyze the methyl esters of Fmoc-Tyr-Leu-OMe, thereby creating Fmoc-Tyr-Leu, which subsequently assembles into supramolecular polymers. Not only does this approach allow for the external triggering of selfassembly, it also creates a system in which the self-assembly rate can be controlled by the amount of enzyme present. The rate of self-assembly influences the morphology of the resulting supramolecular polymer and, thereby, its material properties.

Using supramolecular polymers, researchers have studied the relationship between molecular design and self-assembled structure and their effects on the material properties. For instance, Stupp and co-workers showed that the rigidity of a supramolecular polymer ${ }^{85}$ or the cohesiveness of the fibers ${ }^{86}$ can be tuned by introducing minor mutations in the peptide domain of PA molecules. Better understanding of such molecular design and structure relationships is crucial for the resulting functional properties and could allow researchers to induce different cell behaviors and fates. ${ }^{87}$

Just as native protein folding across multiple length scales leads to the formation of macroscopic protein networks, supramolecular polymers can also be organized on higher length scales. For example, PA molecules were hierarchically assembled in perpendicularly aligned monodomain gels. ${ }^{33}$ The ordering within this hierarchical construct took place over several length scales.

A different hierarchically ordered supramolecular system involved the ordering of a hybrid system of PA nanofibers and an oppositely charged biopolymer ${ }^{88}$ (Figure $3 \mathrm{~b}$ ). A mixture of these two components resulted in the formation of nanofiber bundles aligned perpendicular to the diffusion barrier at the interface of the two solutions. The final structure was a hierarchically ordered membrane with a thickness on the order of 2-20 $\mu \mathrm{m}$ that was organized on two different levels. First, PA molecules were assembled into supramolecular polymers, and second, the supramolecular polymers were aligned perpendicular to the membrane. ${ }^{89}$ The length scale of such constructs was not limited to macroscopic sacs or membranes, but rather, the structures could be downscaled by injecting microdroplets of biopolymer solution into a bath of supramolecular polymers using a picospray setup..$^{90}$ This processing technique resulted in cell-sized hierarchically organized membranes, rather than macroscopic structures. Moreover, using a microemulsion technique, the length scale could be decreased even further to supramolecular-polymer-decorated particles with a diameter of only hundreds of nanometers, ideal for drugdelivery purposes. ${ }^{91}$

Peptide-derived supramolecular polymers offer great flexibility for applications in regenerative medicine, as the selfassembled structures provide the main structural components and various amounts of surface decoration with bioactive or signaling ligands can be doped into the structure. Control over the amino acid sequence allows the formation of domain structures with predisposed assembly at scales well beyond the length of the amino acid blocks. Controlling the peptide sequence or modifying the amino acids with different motifs enables the formation of fibers at the multinanometer scale and gels or higher hierarchical structures at micron and larger length scales. The dimensions of the resulting supramolecular assemblies enable them to mimic some of the components of the ECM and direct cell behavior.

\section{Protein biopolymers and supramolecular polymers as biomaterials for regenerative medicine}

Regenerative medicine aims at developing therapies for the repair or replacement of tissues and organs, thereby restoring function impaired by congenital defects, diseases, trauma, or aging. ${ }^{92}$ One of the goals in this field is the development of functional scaffolds that provide the microenvironment for the growth of cells and tissues. Cells in their natural environment are constantly signaled by surrounding factors to adhere, migrate, proliferate, or differentiate. These signaling molecules can be loosely divided into two groups: soluble factors, including growth factors and small molecules, and insoluble signaling cues that are covalently or noncovalently attached to the ECM. Therefore, in addition to providing physical support, an ideal engineered scaffold would regulate the delivery of bioactive 
factors and participate in signaling to control cell behavior and support tissue structure, growth, and function. In this context, protein biopolymers and bioinspired supramolecular polymers are ideal candidates to fulfill these requirements because of their biocompatibility, degradability, mechanical properties, and signaling capability.

The engineering of delivery matrices composed of biopolymers or supramolecular polymers has attracted extensive research efforts because of the critical role of growth factors in controlling cellular functions and their ability to elicit tissue regeneration. Precise control over the signaling of these factors in space and time could allow control of a regenerative process. ${ }^{29}$ To this end, the natural interactions between ECM proteins and growth factors, specifically the growth-factorbinding sites of $\mathrm{FN},{ }^{93,94}$ enable the use of these domains as a generic approach for delivering growth factors. For example, a multifunctional recombinant fragment of $\mathrm{FN}$ was engineered to integrate a fibrin-binding domain and a growth-factor-binding domain. This multifunctional domain enabled the co-delivery of vascular endothelial growth factor (VEGF) ${ }^{95}$ and plateletderived growth factor (PDGF-BB) and induced angiogenesis at low doses, whereas growth factors delivered without the FN fragment had no significant effect. ${ }^{94}$

Alternatively, different biopolymers, including fibronectin, collagen, and silk, have been used to encapsulate or immobilize growth factors by exploiting electrostatic or other secondary interactions between the biopolymers and the growth factors. For instance, silk has been studied as a potential material to deliver a growth factor able to stimulate the nervous system, thereby facilitating the treatment of peripheral nerve injury (PNI).${ }^{96}$ For successful nerve regeneration after PNI, the axons from the severed nerves need to bridge the gap between the two stumps and restore the original connections. ${ }^{97}$ To increase the success rate, the axon growth can be stimulated by neural growth factors (NGFs) and guided through physical (contact guidance) and chemical (neurotropism) mechanisms. However, the inherent instability of growth factors in vivo poses a challenge. They are also sensitive to degradation during processing and formulation of scaffolds. Therefore, protection and the sustained release of growth factors from silk fibroin scaffolds have been studied to overcome this challenge.

A great advantage of using fibroin to create such biomaterials is its water solubility and ability to form insoluble scaffolds under relatively mild conditions. ${ }^{98,99}$ Such benign aqueous processing allows for the production of relatively sophisticated materials, such as fibroin nerve-guiding conduits loaded with NGF for peripheral nerve repair (Figure 4a). NGF-loaded fibroin matrices exhibit sustained release of the growth factor for weeks and support the adhesion of PC12 cells. Furthermore, silk fibroin scaffolds, loaded with NGF, can support adhesion and promote neurite outgrowth of dorsal root ganglion neurons. ${ }^{102}$ In addition to NGF, silk scaffolds have been studied for the controlled release of insulin-like growth factor I (IGF-I) and bone morphogenetic protein 2 , resulting in the in vitro differentiation of human mesenchymal stem cells into chondrocytes and osteoblasts, respectively. ${ }^{103}$

Alongside biopolymers, supramolecular polymers are also attractive for the delivery of biological factors. Delivery of bioactive factors can be achieved by chemically immobilizing or physically encapsulating them into supramolecular polymer matrices, preventing their denaturation. Their release can be controlled by the degradation rate of the matrices, ${ }^{104}$ their diffusion through the polymer construct, ${ }^{105}$ or external triggers. ${ }^{106}$

In one example, the controlled release of a growth factor from a protected reservoir that relies on biotin/streptavidin interactions was explored. ${ }^{100}$ In this approach, peptides were biotinylated, and the resulting biotin-decorated supramolecular polymers then facilitated the binding of tetravalent streptavidin molecules that could, in turn, coordinate biotinylated IGF-I (Figure 4b). The binding of growth factors to the supramolecular polymers protected them from enzymatic degradation and allowed for prolonged growth-factor delivery and activity. To demonstrate the efficacy of this strategy, the supramolecular polymers were tested in a cell-based therapy using a myocardial infarction mouse model. IGF-I tethered to the supramolecular polymer was injected together with cardiomyocytes (heart muscle cells) into the infarct zone and resulted in a significantly improved systolic (contractile) function of the heart as compared to untethered growth factor. This demonstrated that prolonged release of growth factors by noncovalent binding to a supramolecular polymer can support cell therapies.

Although growth factor delivery matrices show promise in controlling different cellular and regeneration processes, the clinical applications of these proteins are hindered by short degradation half-lives, immune-related side effects, and high costs. An attractive strategy for overcoming some of these challenges is to identify the peptide sequence of the growth factor that binds the cell receptors and attach it to the supramolecular polymer. The peptide domain activates the targeted membrane receptors in the proximity of the scaffold and avoids the use of growth factors. For instance, D'Andrea et al. designed a peptide sequence based on the crystal structure of VEGF bound to its transmembrane receptor. ${ }^{107}$ This binding sequence was coupled to different supramolecular polymers, ${ }^{108,109}$ and the resulting scaffolds were able to mimic the action of VEGF without using the actual growth factor. Stupp and co-workers showed that when the VEGF-mimetic sequence was attached to a PA, the survival, proliferation, and migration of human umbilical vein endothelial cells were significantly improved, as compared to the use of the unmodified supramolecular polymer or the peptide by itself. ${ }^{101}$ The potential of the VEGF-mimetic PA as a therapy for ischemic disease was evaluated using the mouse-hind limb ischemia model (Figure 4c). An improvement in tissue salvage and enhanced motor function and blood perfusion were found after intramuscular injection of these supramolecular polymers, as compared to injection of just the bioactive peptide.

Beyond the ability to deliver soluble signals to the environment, biomaterials for regenerative medicine need to be able 


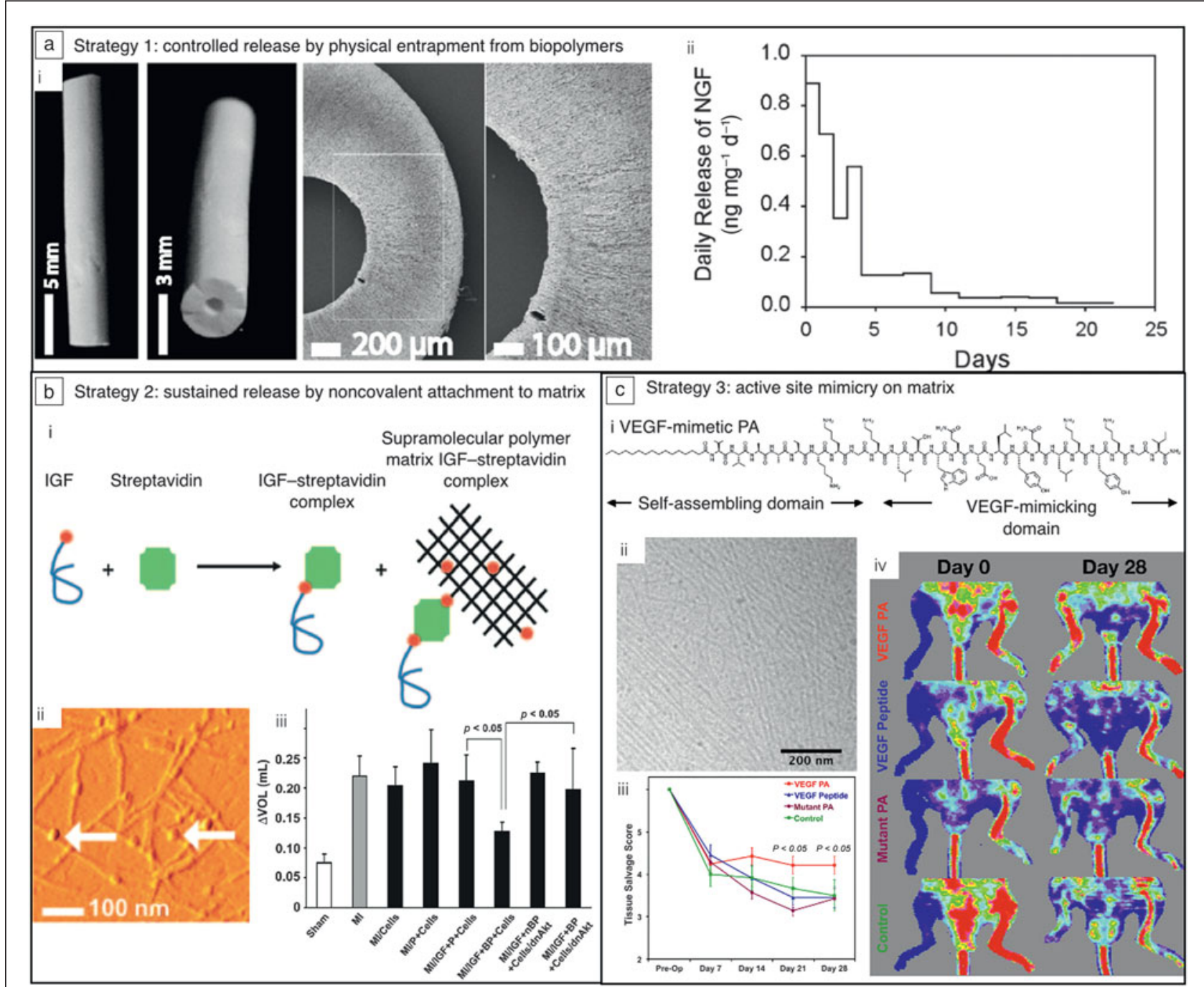

Figure 4. Strategies for the release of growth factors. (a) Growth-factor release by physical entrapment in a nerve conduit. (i) Photographs and scanning electron microscope images of the nerve conduit. (ii) Sustained release of neural growth factor (NGF) from the scaffolds. (b) Sustained release of proteins through noncovalent interactions between the scaffold and the growth factor. (i) Scheme of the supramolecular interaction among biotinylated insulin-like growth factor (IGF), streptavidin, and a biotinlyated peptide as evidenced by (ii) atomic force microscopy. (iii) Ventricular dilation, as measured by the difference in ventricular volume between days 1 and 21 after an induced myocardial infarction was not observed for rats with cells embedded in the IGF-nanofiber construct. (c) Sustained growthfactor efficacy by mimicking the active site of the growth factor. (i) Molecular design of vascular endothelial growth factor- (VEGF-) mimetic peptide. (ii) Cryogenic transmission electron microscope image of the supramolecular polymers formed by the VEGF-mimetic PA. (iii) Tissue salvage score according to the hind limb ischemia model showing a significantly higher tissue salvage for animals treated with VEGF-mimetic PA. (iv) Laser Doppler perfusion imaging shows significantly higher perfusion ratios for the VEGF-mimetic PA as compared to controls. (a) Reproduced with permission from Reference 99. (c) 2007 Elsevier. (b) Reproduced with permission from Reference 100. (c) 2006 National Academy of Sciences. (c) Reproduced with permission from Reference 101. () 2012 National Academy of Sciences.

to signal cells to undergo different processes such as adhesion, proliferation, migration, and differentiation. Cell adhesion is the biomimetic function most commonly incorporated in biomaterial design. Initially, this was achieved by merely coating scaffolds with biopolymers known to promote cell adhesion and spreading. ${ }^{110,111}$ Biopolymers such as FN, ${ }^{112}$ laminin, ${ }^{113}$ vitronectin, ${ }^{114}$ tenascin, ${ }^{115}$ and certain collagens ${ }^{116}$ are known to facilitate cell adhesion and spreading through conserved amino acid sequences such as RGDS (Arg-Gly-Asp-Ser, where Arg is arginine, Gly is glycine, Asp is aspartic acid, and Ser is serine) that can be recognized by the transmembrane integrin proteins. In the case of $\mathrm{FN}$, integrin recognition and polymer self-assembly are reciprocal: Whereas cell adhesion depends on interaction with the FN matrix, FN matrix formation can occur only after soluble FN interacts with integrins on the cell surface (Figure 5a). ${ }^{117}$ Although this process is not fully understood, FN polymerization can be divided into two phases: nucleation and subsequent elongation. It is hypothesized that the binding of the RGDS sequence in FN drives nucleation, as recombinant FN that lacks the sequence cannot form fibrils. ${ }^{120}$ Integrin binding to the RGDS sequence initiates an intracellular cascade resulting in the formation of focal 


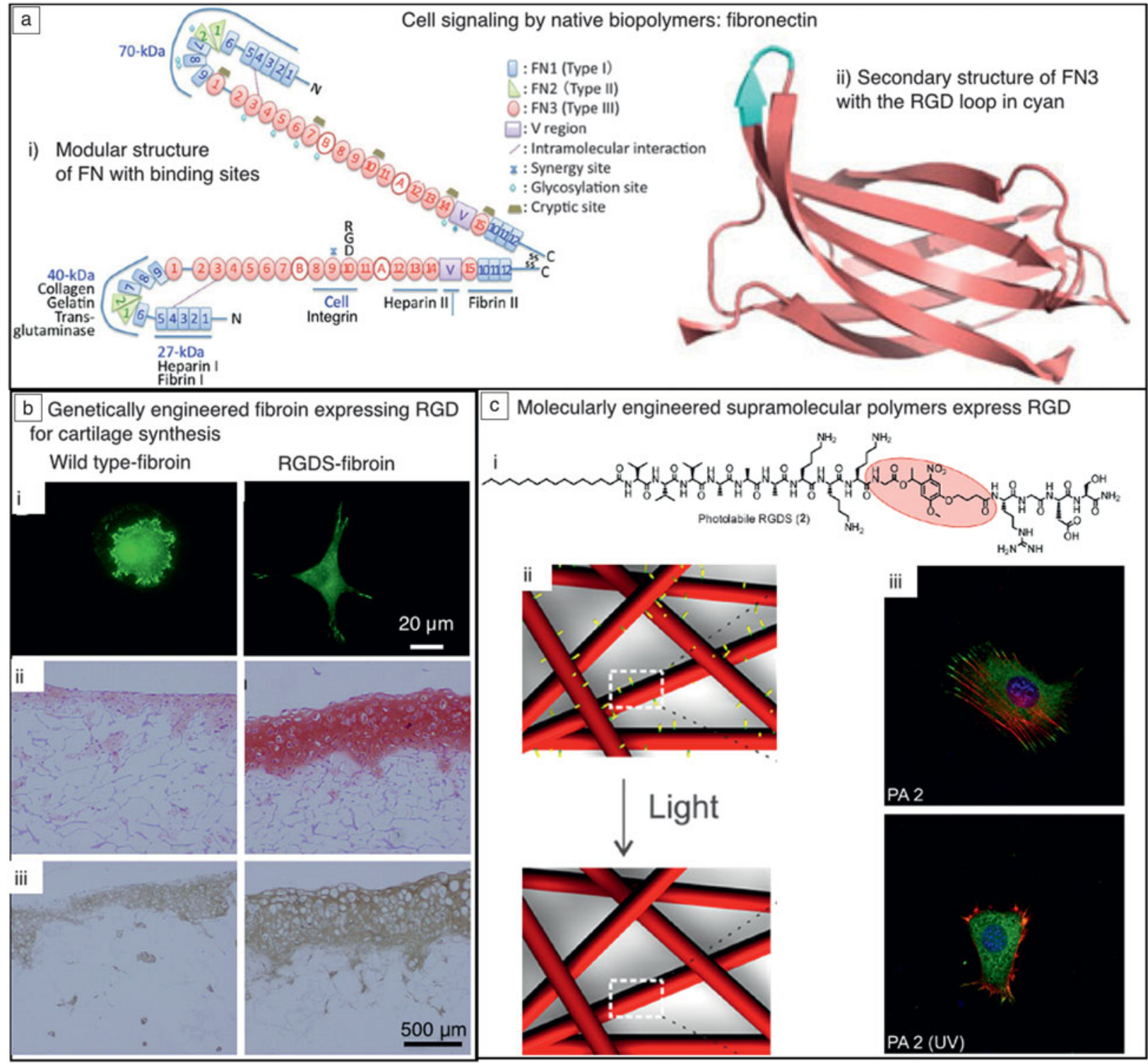

Figure 5. Strategies for signaling cells using biopolymers or supramolecular polymers. (a) Native cell-signaling peptides can be identified from extracellular matrix proteins, such as the RGD (Arg-Gly-Asp, where Arg is arginine, Gly is glycine, and Asp is aspartic acid) sequence in fibronectin. (b) (i) The RGD cell-signaling domain can be genetically engineered to be expressed by silkworms in the fibroin L-chain to significantly enhance cell adhesion compared to that in wild-type fibroin. Photographs of regenerated cartilage stained by (ii) Safranin-O or (iii) collagen Type I immunostaining show enhanced cartilage regeneration on fibroin with RGD. (c) RGD can also be covalently engrafted on supramolecular polymers, such as (i) a PA construct. In this specific case, RGDS (Arg-Gly-Asp-Ser, where Ser is serine) is attached by a photocleavable linker. (ii) Upon irradiation with UV light, the PA supramolecular polymers in the fibrous network shed their RGDS functional groups, rendering them biologically inactive. (iii) Cells immobilized on the PA construct before (PA 2) and after (PA 2 [UV]) exposure to UV light as imaged by confocal microscopy. (a) Reproduced with permission from Reference 41. ( 2011 Springer. (b) Reproduced with permission from Reference 118. () 2010 Elsevier. (c) Reproduced with permission from Reference 119. () 2012 American Chemical Society.

adhesions (cell-matrix adhesion points) allowing cells to attach and exert force on the surrounding matrix. ${ }^{121}$ This feature is extremely useful, as it permits the incorporation of these sequences into synthetic systems, thus rendering them bioactive.

The most commonly applied peptide is the RGDS sequence, which has been incorporated into various polymers to render them bioactive. ${ }^{122}$ For the scope of this article, we focus only on examples of bioactivation of silk and supramolecular polymers with peptide cues. In the context of silk, Kaplan and co-workers showed that fibroin films can be chemically derivatized with RGD. These films were found to significantly upregulate bone formation as compared to controls without RGD. ${ }^{123}$ It was also shown that porous silk scaffolds functionalized with RGD can induce osteogenesis of human mesenchymal stem cells (differentiation into bone-forming osteoblasts). ${ }^{124}$ 
In conjunction with RGD functionalization, the surface patterning of silk facilitates the control of cell alignment on scaffolds. ${ }^{125}$ Such work shows the power of bioactivation and the potential of silk as a biomaterial for tissue reconstruction.

Scaffolds fabricated from recombinant silk proteins have also produced encouraging results in enabling attachment and growth of cells in vitro. ${ }^{126}$ The recombinant production of silk-inspired proteins allows for flexibility in the engineering of the protein sequence. For example, new proteins can be designed utilizing repetitive domains drawn from silkworm or spider silks in combination with sequences such as RGD. ${ }^{127-130}$ Kambe et al. genetically fused the RGD sequence into the silk fibroin light chain. ${ }^{118}$ To study whether the RGD was accessible for cells, researchers found more attached chondrocytes (cartilage-producing cells) on the RGD fibroin as compared to wild-type fibroin (Figure 5b). The success in the application of silk fibroin in tissue engineering and the biomedical field in general has seeded considerable interest in the further development of these materials for medical devices and therapeutic treatments. Silk fibroin mesh structures (e.g., SERI Surgical Scaffold, from Allergan) are currently in clinical use as bioresorbable surgical scaffolds. In addition to its use as a fiber, a number of companies are pursuing silk fibroin solutions or silk-based materials for soft-tissue repair, the treatment of osteoarthritis, cartilage repair (currently in clinical trials), vascular grafts, and nerve regeneration. Recombinant spider silk proteins are also being commercially developed for tissueengineering and wound-healing applications (e.g., AMSilk and Spiber Technologies).

Bioactivation of materials by incorporating bioactive cues can also be applied to supramolecular polymers. For instance, the previously mentioned RGDS peptide has been applied on self-assembling PAs, ${ }^{131}$ Fmoc-peptide-based supramolecular polymers, ${ }^{132}$ self-assembling DNA nanotubes, ${ }^{133}$ and many others. Moreover, additional bioactive peptide sequences derived from collagen, ${ }^{134}$ laminin, ${ }^{80}$ and non-ECM proteins ${ }^{135,136}$ can also be used to increase the bioactivity of supramolecular polymers.

One goal when developing supramolecular polymers to mimic the ECM is to recapitulate the dynamic features of the native environment. Even though the ECM might seem static, ECM fibers are constantly broken down by enzymatic degradation, and new fibers are secreted by the cells. This homeostasis allows the tissue to change the composition of the ECM when necessary, for instance, in the case of wound healing or development. Although some supramolecular-polymer-based materials have been developed to mimic the native ECM dynamics, ${ }^{119,137}$ this feature remains a challenge. For instance, Sur and co-workers bioactivated a supramolecular polymer with an RGDS cue using a photocleavable linker (Figure 5c). Fibroblast cells recognized the RGDS cue, resulting in spreading, as expected. However, upon irradiation of the supramolecular polymers with light, the cues were shed, resulting in a loss of bioactivity. ${ }^{119}$ Although the dynamics in these examples and others ${ }^{138,139}$ are in stark contrast to the dynamics found in vivo, these strategies open up pathways to materials that display bioactivity on demand.

\section{Conclusions and outlook}

The selection of a bioactive biomaterial for tissue engineering and regenerative medicine is of great importance, because its structure can determine the functionality of the tissue formed and, when used as a scaffold seeded with cells, it will greatly influence engraftment with host tissues. Overall, for a material to serve as a synthetic ECM, a few basic requirements are necessary, especially biodegradability and biocompatibility. The degradation kinetics must be compatible with the rate of tissue regeneration and restoration of function, and the materials used need to have the necessary mechanical integrity. The scaffold should also integrate and interact with the surrounding host tissues without eliciting an immunological response. Biomaterials and scaffolds must also allow easy diffusion of nutrients and cellular waste products and allow cell penetration and tissue ingrowth/outgrowth depending on the application. Biomaterials for regeneration should guide the appropriate cell response, deliver the required soluble factors, recruit endogenous cells, and in most cases induce vascularization. Finally, for biomaterials to be translated from the laboratory to the clinic, they should be easy to handle, manufacture, store, sterilize, package, and transport.

Proteins, peptides, and supramolecular polymers have emerged as attractive candidates for the fabrication of scaffolds for tissue engineering and regenerative medicine. They exhibit beneficial interactions with cells and have great potential as hydrogels. The mechanical properties, patternability, and biochemistry of ECM- and silk-derived proteins make these biomolecules ideal for the direction of cell behaviors, including adhesion, proliferation, migration, and differentiation. Scaffolds based on collagen and silk proteins have been shown to induce minimal immune and inflammatory responses when implanted in the body, ${ }^{140-142}$ are mechanically robust, and can be proteolytically degraded into nontoxic amino acids.

Silk fibroin derived from B. mori cocoons is a US Food and Drug Administration-approved biomaterial that is relatively inexpensive and widely available. The ability of silk fibroin to stabilize and deliver different molecules (e.g., growth factors, antibiotics, and vaccines) is of particular interest and holds tremendous promise for tissue engineering and other biomedical applications. ${ }^{143}$

The properties of silk and collagen make these materials attractive for further advances in the manufacturing of tissue engineering scaffolds, includng additive manufacturing. Indeed, fibroin/collagen solutions have been successfully applied as the base materials in the bioprinting of chondrocyte cells. ${ }^{144}$ These advances hint at the possibilities of collagen- and silk-based clinical tissue regeneration work and commercialization in the future. The recombinant production of collagen- and spidroininspired proteins has progressed significantly and allows for the engineering of designer proteins with multiple functionalities. However, the high relative costs of these recombinant 
proteins currently limit their availability to the greater research community.

As biomaterials, supramolecular polymers are versatile materials that can be designed to mimic specific aspects of biopolymers by utilizing noncovalent interactions to direct the self-assembly of molecular building blocks. Specifically, selfassembling peptides offer numerous advantages as versatile and efficient biomaterials. Inspired by biological signaling, supramolecular polymers have been decorated with different bioactive peptide sequences for a variety of regenerative medicine applications. Furthermore, peptide biomaterials can biodegrade rapidly by hydrolytic and enzymatic processes into natural amino acids.

The hierarchical assembly of peptide-based materials enables the crafting of materials organized from molecular to macroscopic scales. As an example, Stupp and co-workers' monodomain gels can molecularly instruct cells to elicit a specific biological response by using peptide epitopes, but they can also instruct cells at the macroscopic scale to migrate along a specific direction. ${ }^{33}$

Multiple-length-scale signaling to cells is of crucial importance in regenerative medicine, especially when functional recovery is about spatial control as it is for the regeneration of nervous tissue. Two important examples are spinal cord injury ${ }^{145,146}$ and the regeneration of peripheral nerves. ${ }^{147-149}$ The number of hierarchically organized materials remains limited so far, mainly because of a lack of design rules for the formation of hierarchical structures. Although great progress has been made on rules for the self-assembly of molecules into nanostructures, adequate design rules that predict their assembly into hierarchically ordered structures across various length scales are currently not available (with some exceptions ${ }^{150}$ ).

Another horizon in the field of supramolecular polymers is the development of stimuli-responsive dynamic materials. Self-assembled supramolecular architectures are optimal candidates for creating dynamic materials because the building blocks are not covalently fixed, and the supramolecular forces that hold them together can be reconfigured to change their properties. Engineering dynamic triggers that allow changes in the physical structure and chemical composition of a synthetic matrix would be highly advantageous in mimicking the dynamic features of the ECM. This field will continue to expand to create such functionally powerful materials, possibly combining macromolecules and supramolecular structures.

\section{Acknowledgments}

Experimental work in the Stupp laboratory related to bioactive and bioinspired materials was supported by grants from the US National Institutes of Health (National Institute of Biomedical Imaging and Bioengineering, NIBIB/BRP Award 3R01EB003806-09S1; National Heart, Lung, and Blood Institute, NHLBI/BRP Awards 5R01HL116577-02 and NHLBI/PPG Award 5P01HL108795-04; and National Institute of Dental and Craniofacial Research, NIDCR Award 5R01DE015920-09); the Department of Energy Office of Basic Energy Sciences under Award DE-FG02-00ER45810; the Center for Bio-Inspired Energy Science, an Energy Frontier Research Center funded by the US Department of Energy, Office of Science, Basic Energy Sciences, under Award DE-SC0000989; and the National Science Foundation under Award DMR-1006713-004. M.D. and R.R.N. thank Kristi M. Singh (Air Force Research Laboratory [AFRL]) for assistance in the editing of this manuscript. M.D. and R.R.N. gratefully acknowledge support from AFRL and the Air Force Office of Scientific Research.

\section{References}

1. C. Frantz, K.M. Stewart, V.M. Weaver, J. Cell Sci. 123, 4195 (2010).

2. H. Järveläinen, A. Sainio, M. Koulu, T.N. Wight, R. Penttinen, Pharmacol. Rev. 61, 198 (2009).

3. L. Schaefer, R.M. Schaefer, Cell Tissue Res. 339, 237 (2010).

4. T.H. Barker, Biomaterials 32, 4211 (2011).

5. J. Glowacki, S. Mizuno, Biopolymers 89, 338 (2008).

6. J.J. Song, H.C. Ott, Trends Mol. Med. 17, 424 (2011).

7. D.C. Roy, D.C. Hocking, Tissue Eng. Part A 19, 558 (2013)

8. K.E. Kadler, D.F. Holmes, J.A. Trotter, J.A. Chapman, Biochem. J. 316, 1 (1996).

9. R.0. Hynes, Cell 69, 11 (1992).

10. A.J. Garcia, M.D. Vega, D. Boettiger, Mol. Biol. Cell 10, 785 (1999).

11. N. Kasoju, U. Bora, Adv. Healthcare Mater. 1, 393 (2012).

12. M. Heim, D. Keerl, T. Scheibel, Angew. Chem. Int. Ed. 48, 3584 (2009).

13. G.H. Altman, F. Diaz, C. Jakuba, T. Calabro, R.L. Horan, J. Chen, H. Lu, J. Richmond, D.L. Kaplan, Biomaterials 24, 401 (2003).

14. G. Charras, E. Sahai, Nat. Rev. Mol. Cell Biol. 15, 813 (2014).

15. E. Cukierman, R. Pankov, D.R. Stevens, K.M. Yamada, Science 294, 1708 (2001). 16. A. Shaub, Nat. Cell Biol. 1, E173 (1999).

17. T. Gulik-Krzywicki, C. Fouquey, J.M. Lehn, Proc. Natt. Acad. Sci. U.S.A. 90, 163 (1993).

18. R.P. Sijbesma, F.H. Beijer, L. Brunsveld, B.J.B. Folmer, J.H.K.K. Hirschberg, R.F.M. Lange, J.K.L. Lowe, E.W. Meijer, Science 278, 1601 (1997).

19. E.A. Fogleman, W.C. Yount, J. Xu, S.L. Craig, Angew. Chem. Int. Ed. 41, 4026 (2002).

20. T. Park, S.C. Zimmerman, J. Am. Chem. Soc. 128, 13986 (2006).

21. C.C. Chen, E.E. Dormidontova, J. Am. Chem. Soc. 126, 14972 (2004).

22. S.J. Rowan, J.B. Beck, Polym. Prepr. 46, 1164 (2005).

23. A. Noro, S. Matsushima, X.D. He, M. Hayashi, Y. Matsushita, Macromolecules 46, 8304 (2013).

24. S. Burattini, B.W. Greenland, D.H. Merino, W. Weng, J. Seppala, H.M. Colquhoun, W. Hayes, M.E. Mackay, I.W. Hamley, S.J. Rowan, J. Am. Chem. Soc. 132, 12051 (2010).

25. M. Miyauchi, A. Harada, J. Am. Chem. Soc. 126, 11418 (2004).

26. M. Miyauchi, Y. Takashima, H. Yamaguchi, A. Harada, J. Am. Chem. Soc. 127, 2984 (2005).

27. R.M. Yebeutchou, F. Tancini, N. Demitri, S. Geremia, R. Mendichi, E. Dalcanale, Angew. Chem. Int. Ed. 47, 4504 (2008).

28. A. Barnard, D.K. Smith, Angew. Chem. Int. Ed. 51, 6572 (2012).

29. J. Boekhoven, S.I. Stupp, Adv. Mater. 26, 1642 (2014).

30. E. Busseron, Y. Ruff, E. Moulin, N. Giuseppone, Nanoscale 5, 7098 (2013).

31. M.J. Buehler, J. Mech. Behav. Biomed. Mater. 1, 59 (2008).

32. R.M. Schulz, A. Bader, Eur. Biophys. J. 36, 539 (2007).

33. S. Zhang, M.A. Greenfield, A. Mata, L.C. Palmer, R. Bitton, J.R. Mantei, C. Aparicio, M. Olvera de la Cruz, S.I. Stupp, Nat. Mater. 9, 594 (2010).

34. B.F. Campbell, M.R. Chance, J.M. Friedman, Science 238, 373 (1987).

35. M. Van der Rest, R. Garrone, FASEB J. 5, 2814 (1991).

36. A. Gautieri, S. Vesentini, A. Redaelli, M.J. Buehler, Nano Lett. 11, 757 (2011). 37. A.F. Oberhauser, C. Badilla-Fernandez, M. Carrion-Vazquez, J.M. Fernandez, J. Mol. Biol. 319, 433 (2002).

38. E. Klotzsch, M.L. Smith, K.E. Kubow, S. Muntwyler, W.C. Little, F. Beyeler, D. Gourdon, B.J. Nelson, V. Vogel, Proc. Natl. Acad. Sci. U.S.A. 106, 19267 (2009).

39. Y. Mao, J.E. Schwarzbauer, Matrix Biol. 24, 389 (2005).

40. J. Sottile, D.C. Hocking, Mol. Biol. Cell 13, 3546 (2002)

41. J. Xu, D. Mosher, in The Extracellular Matrix: An Overview, R.P. Mecham, Ed. (Springer, Berlin, 2011), pp. 41-75.

42. E. Engvall, E. Ruoslahti, Int. J. Cancer 20, 1 (1977).

43. J.E. Schwarzbauer, J.L. Sechler, Curr. Opin. Cell Biol. 11, 622 (1999).

44. I. Wierzbicka-Patynowski, J.E. Schwarzbauer, J. Cell Sci. 116, 3269 (2003).

45. M. Heim, L. Romer, T. Scheibel, Chem. Soc. Rev. 39, 156 (2010).

46. Z. Shao, F. Vollrath, Nature 418, 741 (2002).

47. G. Xu, L. Gong, Z. Yang, X.Y. Liu, Soft Matter 10, 2116 (2014).

48. S. Keten, Z. Xu, B. Ihle, M.J. Buehler, Nat. Mater. 9, 359 (2010). 
49. T. Asakura, Y. Suzuki, Y. Nakazawa, K. Yazawa, G.P. Holland, J.L. Yarger, Prog. Nucl. Magn. Reson. Spectrosc. 29, 23 (2013).

50. J.G. Hardy, L.M. Romer, T.R. Scheibel, Polymer 49, 4309 (2008).

51. D.N. Rockwood, R.C. Preda, T. Yucel, X. Wang, M.L. Lovett, D.L. Kaplan, Nat. Protoc. 6, 1612 (2011).

52. A. Rising, M. Widhe, J. Johansson, M. Hedhammar, Cell. Mol. Life Sci. 68 , 169 (2011)

53. R.V. Lewis, Chem. Rev. 106, 3762 (2006).

54. L. Eisoldt, A. Smith, T. Scheibel, Mater. Today 14, 80 (2011)

55. O. Tokareva, V.A. Michalczechen-Lacerda, E.L. Rech, D.L. Kaplan, Microb. Biotechnol. 6, 651 (2013)

56. A. Heidebrecht, T. Scheibel, Adv. Appl. Microbiol. 82, 115 (2013).

57. L. Brunsveld, B.J.B. Folmer, E.W. Meijer, R.P. Sijbesma, Chem. Rev. 101, 4071 (2001).

58. T. Aida, E.W. Meijer, S.I. Stupp, Science 335, 813 (2012).

59. P.Y. Dankers, M.C. Harmsen, L.A. Brouwer, M.J. van Luyn, E.W. Meijer, Nat. Mater. 4, 568 (2005).

60. J.D. Hartgerink, E. Beniash, S.I. Stupp, Science 294, 1684 (2001).

61. E.R. Zubarev, M.U. Pralle, E.D. Sone, S.I. Stupp, J. Am. Chem. Soc. 123, 4105 (2001).

62. J.D. Hartgerink, E. Beniash, S.I. Stupp, Proc. Natl. Acad. Sci. U.S.A. 99, 5133 (2002).

63. S.I. Stupp, R.H. Zha, L.C. Palmer, H. Cui, R. Bitton, Faraday Discuss. 166, 9 (2013).

64. Y. Yamamoto, T. Fukushima, Y. Suna, N. Ishii, A. Saeki, S. Seki, S. Tagawa, M. Taniguchi, T. Kawai, T. Aida, Science 314, 1761 (2006).

65. M.R. Ghadiri, J.R. Granja, R.A. Milligan, D.E. McRee, N. Khazanovich, Nature 366, 324 (1993)

66. J.D. Hartgerink, J.R. Granja, R.A. Milligan, M.R. Ghadiri, J. Am. Chem. Soc. 118, 32 (1996).

67. L.E.R. O'Leary, J.A. Fallas, E.L. Bakota, M.K. Kang, J.D. Hartgerink, Nat. Chem. 3, 821 (2011)

68. A. Aggeli, M. Bell, N. Boden, J.N. Keen, P.F. Knowles, T.C.B. Mcleish, M. Pitkeathly, S.E. Radford, Nature 386, 259 (1997).

69. G.A. Di Lullo, S.M. Sweeney, J. Korkko, L. Ala-Kokko, J.D. San Antonio, J. Biol. Chem. 277, 4223 (2002).

70. M.M. Pires, D.E. Przybyla, J. Chmielewski, Angew. Chem. Int. Ed. 28, 7813 (2009).

71. Y. Suzuki, T. Yamazaki, A. Aoki, H. Shindo, T. Asakura, Biomacromolecules 15 (1), 104 (2014).

72. S. Zhang, A. Rich, Proc. Natl. Acad. Sci. U.S.A. 94, 23 (1997).

73. H. Yokoi, T. Kinoshita, S. Zhang, Proc. Natl. Acad. Sci. U.S.A. 102, 8414 (2005).

74. A.R. Cormier, X. Pang, M.I. Zimmerman, H.X. Zhou, A.K. Paravastu, ACS Nano 7. 7562 (2013)

75. A. Horii, X. Wang, F. Gelain, S. Zhang, PLoS One 2, e190 (2007)

76. A.R. Hirst, S. Roy, M. Arora, A.K. Das, N. Hodson, P. Murray, S. Marshall, N. Javid, J. Sefcik, J. Boekhoven, J.H. van Esch, S. Santabarbara, N.T. Hunt, R.V. Ulijn, Nat. Chem. 2, 1089 (2010).

77. R.G. Ellis-Behnke, Y.X. Liang, S.W. You, D.K. Tay, S. Zhang, K.-F. So, G.E. Schneider, Proc. Natl. Acad. Sci. U.S.A. 103, 5054 (2006).

78. X. Zhao, S. Zhang, Chem. Soc. Rev. 35, 1105 (2006).

79. Y.S. Velichko, S.I. Stupp, M.O. de la Cruz, J. Phys. Chem. B 112, 2326 (2008).

80. G.A. Silva, C. Czeisler, K.L. Niece, E. Beniash, D.A. Harrington, J.A. Kessler, S.I. Stupp, Science 303, 1352 (2004).

81. M.O. Guler, S.I. Stupp, J. Am. Chem. Soc. 129, 12082 (2007).

82. S. Fleming, R.V. Ulijn, Chem. Soc. Rev. 43, 8150 (2014).

83. V. Jayawarna, M. Ali, T.A. Jowitt, A.F. Miller, A. Saiani, J.E. Gough, R.V. Ulijn, Adv. Mater. 18, 611 (2006).

84. M. Reches, E. Gazit, Science 300, 625 (2003)

85. E.T. Pashuck, H. Cui, S.I. Stupp, J. Am. Chem. Soc. 132, 6041 (2010).

86. C.J. Newcomb, S. Sur, J.H. Ortony, O.-S. Lee, J.B. Matson, J. Boekhoven, J.M. Yu, G.C. Schatz, S.I. Stupp, Nat. Commun. 5, 3321 (2014).

87. D.E. Discher, P. Janmey, Y.L. Wang, Science 310, 1139 (2005)

88. R.M. Capito, H.S. Azevedo, Y.S. Velichko, A. Mata, S.I. Stupp, Science 319, 1812 (2008).

89. D. Carvajal, R. Bitton, J.R. Mantei, Y.S. Velichko, S.I. Stupp, K.R. Shull, Soft Matter 6, 1816 (2010)

90. D.I. Rożkiewicz, B.D. Myers, S.I. Stupp, Angew. Chem. Int. Ed. 123, 6448 (2011).

91. J. Boekhoven, R.H. Zha, F. Tantakitti, E. Zhuang, R. Zandi, C.J. Newcomb, S.I. Stupp, RSC Adv. 5, 8753 (2015)

92. K.R. Chien, Nature 453, 302 (2008).

93. F. Lin, X.-D. Ren, Z. Pan, L. Macri, W.-X. Zong, M.G. Tonnesen, M. Rafailovich, D. Bar-Sagi, R.A.F. Clark, J. Invest. Dermatol. 131, 84 (2011).

94. E.S. Wijelath, J. Murray, S. Rahman, Y. Patel, A. Ishida, K. Strand, S. Aziz,

C. Cardona, W.P. Hammond, G.F. Savidge, S. Rafii, M. Sobel, Circ. Res. 91, 25 (2002).
95. K. Lee, E.A. Silva, D.J. Mooney, J. R. Soc. Interface 8, 153 (2011)

96. S. Guena, I. Perroteau, P. LoS, B. Battsiton, Eds., Tissue Engineering of the Peripheral Nerve: Biomaterials and Physical Therapy (Elsevier, New York, 2013).

97. K. Horch, J. Neurophysiol. 42, 1437 (1979).

98. R. Nazarov, H.J. Jin, D.L. Kaplan, Biomacromolecules 5, 718 (2004)

99. L. Uebersax, M. Mattotti, M. Papaloïzos, H.P. Merkle, B. Gander, L. Meinel, Biomaterials 28, 4449 (2007).

100. M.E. Davis, P.C. Hsieh, T. Takahashi, Q. Song, S. Zhang, R.D. Kamm, A.J. Grodzinsky, P. Anversa, R.T. Lee, Proc. Natl. Acad. Sci. U.S.A. 103, 8155 (2006).

101. M.J. Webber, J. Tongers, C.J. Newcomb, K.-T. Marquardt, J. Bauersachs, D.W. Losordo, S.I. Stupp, Proc. Natl. Acad. Sci. U.S.A. 108, 13438 (2011).

102. V. Benfenati, K. Stahl, C. Gomis-Perez, S. Toffanin, A. Sagnella, R. Torp, D.L. Kaplan, G. Ruani, F.G. Omenetto, R. Zamboni, M. Muccini, Adv. Funct. Mater. 22, 1871 (2012).

103. E. Wenk, H.P. Merkle, L. Meinel, J. Control. Release 150, 128 (2011).

104. J.B. Matson, S.I. Stupp, Chem. Commun. 47, 7962 (2011).

105. J. Kisiday, M. Jin, B. Kurz, H. Hung, C. Semino, S. Zhang, A.J. Grodzinsky, Proc. Natl. Acad. Sci. U.S.A. 99, 9996 (2002).

106. J. Boekhoven, M. Koot, T.A. Wezendonk, R. Eelkema, J.H. van Esch, J. Am. Chem. Soc. 134, 19098 (2012).

107. L.D. D'Andrea, G. laccarino, R. Fattorusso, D. Sorriento, C. Carannante, D. Capasso, B. Trimarco, C. Pedone, Proc. NatI. Acad. Sci. U.S.A. 102, 14215 (2005)

108. X. Wang, A. Horii, S. Zhang. Soft Matter 4, 2388 (2008).

109. X. Liu, X. Wang, A. Horii, X. Wang, L. Qiao, S. Zhang, F.-Z. Cui, Nanoscale 4, 2720 (2012).

110. R.J. Klebe, Nature 250, 248 (1974).

111. E. Pearlstein, Science 262, 497 (1976).

112. M.D. Pierschbacher, E. Ruoslahti, Nature 309, 30 (1984)

113. E. Ruoslahti, M.D. Pierschbacher, Science 238, 491 (1987)

114. E.G. Hayman, M.D. Pierschbacher, S. Suzuki, E. Ruoslahti, Exp. Cell Res. 160 (2), 245 (1985)

115. M.M. Lots, C.A. Burdsal, H.P. Erickson, D.R. McClay, J. Cell Biol. 109, 1795 (1989)

116. H.K. Kleiman, R.J. Klebe, G.R. Martin, J. Cell Biol. 88, 473 (1981).

117. S. Johansson, G. Svineng, K. Wennerberg, A. Armulik, L. Lohikangas, Front. Biosci. 2, d126 (1997).

118. Y. Kambe, K. Yamamoto, K. Kojima, Y. Tamada, N. Tomita, Biomaterials 31, 7503 (2010).

119. S. Sur, J.B. Matson, M.J. Webber, C.J. Newcomb, S.I. Stupp, ACS Nano 6 (12), 10776 (2012)

120. J.L. Sechler, Y. Takada, J.E. Schwarzbauer, J. Cell Biol. 134, 573 (1996)

121. E.F. Plow, T.A. Haas, L. Zhang, J. Loftus, J.W. Smith, J. Biol. Chem. 275 , 21785 (2000).

122. U. Hersel, C. Dahmen, H. Kessler, Biomaterials 24, 4385 (2003).

123. S. Sofia, M.B. McCarthy, G. Gronowicz, D.L. Kaplan, J. Biomed. Mater. Res. 54, 139 (2001)

124. L. Meinel, V. Karageorgiou, S. Hofmann, R. Fajardo, B. Snyder, C. Li, L. Zichner, R. Langer, G. Vunjak-Novakovic, D.L. Kaplan, J. Biomed. Mater. Res. A 71, 25 (2004)

125. E.S. Gil, B.B. Mandal, S.H. Park, J.K. Marchant, F.G. Omenetto, D.L. Kaplan, Biomaterials 31, 8953 (2010).

126. M. Widhe, J. Johansson, M. Hedhammar, Biopolymers 97, 468 (2012).

127. S. Wohlrab, S. Müller, A. Schmidt, S. Neubauer, H. Kessler, A. Leal-Egaña, T. Scheibel, Biomaterials 33, 6650 (2012).

128. M. Yang, C. Tanaka, K. Yamauchi, K. Ohgo, M. Kurokawa, T. Asakura, J. Biomed. Mater. Res. A 84, 353 (2008).

129. E. Bini, C.W. Foo, J. Huang, V. Karageorgiou, B. Kitchel, D.L. Kaplan, Biomacromolecules 7, 3139 (2006).

130. C. Tanaka, T. Asakura, Biomacromolecules 10, 923 (2009).

131. M.J. Webber, J. Tongers, M.A. Renault, J.G. Roncalli, D.W. Losordo, S.I. Stupp, Acta Biomater. 6, 3 (2010).

132. M. Zhou, A.M. Smith, A.K. Das, N.W. Hodson, R.F. Collins, R.V. Ulijn, J.E. Gough, Biomaterials 30, 2523 (2009).

133. N. Stephanopoulos, R. Freeman, H.A. North, S. Sur, S.J. Jeong, F. Tantakitti, J.A. Kessler, S.I. Stupp., Nano Lett. 15, 603 (2015).

134. R.L. Saunders, D.A. Hammer, Cell. Mol. Bioeng. 3, 60 (2010).

135. R.H. Zha, S. Sur, J. Boekhoven, H.Y. Shi, M. Zhang, S.I. Stupp, Acta Biomater. 12, 1 (2015).

136. R.N. Shah, N.A. Shah, M.M. Del Rosario Lim, C. Hsieh, G. Nuber, S.I. Stupp, Proc. Natl. Acad. Sci. U.S.A. 107, 3293 (2010).

137. S. Khan, S. Sur, P.Y. Dankers, R.M. da Silva, J. Boekhoven, T.A. Poor, S.I. Stupp, Bioconjug. Chem. 25, 707 (2014).

138. J. Boekhoven, C.M. Rubert Pérez, S. Sur, A. Worthy, S.I. Stupp, Angew. Chem. Int. Ed. 52 (46), 12077 (2013). 
139. Q. An, J. Brinkmann, H. Juskens, S. Krabbenborg, J. de Boer, P. Jonkheijm, Angew. Chem. Int. Ed. 51, 12233 (2012).

140. G. Charriere, M. Bejot, L. Schnitzler, G. Ville, D.J. Hartmann, J. Am. Acad. Dermatol. 21, 1203 (1989).

141. W.H. Eaglstein, O.M. Alvarez, M. Auletta, D. Leffel, G.S. Rogers, J.A. Zitelli, J.E. Norris, I. Thomas, M. Irondo, J. Fewkes, J. Hardin-Young, R.G. Duff, M.L. Sabolinski, Dermatol. Surg. 25, 195 (1999).

142. S.F. Badylak, T.W. Gilbert, Semin. Immunol. 20, 109 (2008).

143. E.M. Pritchard, P.B. Dennis, F. Omenetto, R.R. Naik, D.L. Kaplan, Biopolymers 97, 279 (2012).

144. S. Das, F. Pati, Y.-J. Choi, G. Rijal, J.-H. Shim, S.W. Kim, A.R. Ray, D.-W. Cho, S. Ghosh, Acta Biomater. 11, 233 (2015).
145. E.J. Berns, S. Sur, L. Pan, J.E. Goldberger, S. Suresh, S. Zhang, J.A. Kessler, S.I. Stupp, Biomaterials 35, 185 (2014).

146. L. Pan, H.A. North, V. Sahni, S.J. Jeong, T.L. McGuire, E. Berns, S.I. Stupp, J.A. Kessler, PLoS One 9, e104335 (2014).

147. N. Angeloni, C.W. Bond, D. Harrington, S.I. Stupp, C.A. Podlasek, J. Sex. Med. 10, 1240 (2013).

148. C.W. Bond, N. Angeloni, D. Harrington, S.I. Stupp, C.A. Podlasek, J. Sex. Med. 10, 730 (2013).

149. A. Li, A. Hokugo, A. Yalom, E.J. Berns, N. Stephanopoulos, M.T. McClendon, L.A. Segovia, I. Spigelman, S.I. Stupp, R. Jarrahy, Biomaterials 35, 8780 (2014). 150. H. Cui, E.T. Pashuck, Y.S. Velichko, S.J. Weigand, A.G. Cheetham, C.J. Newcomb, S.I. Stupp, Science 327, 555 (2010).

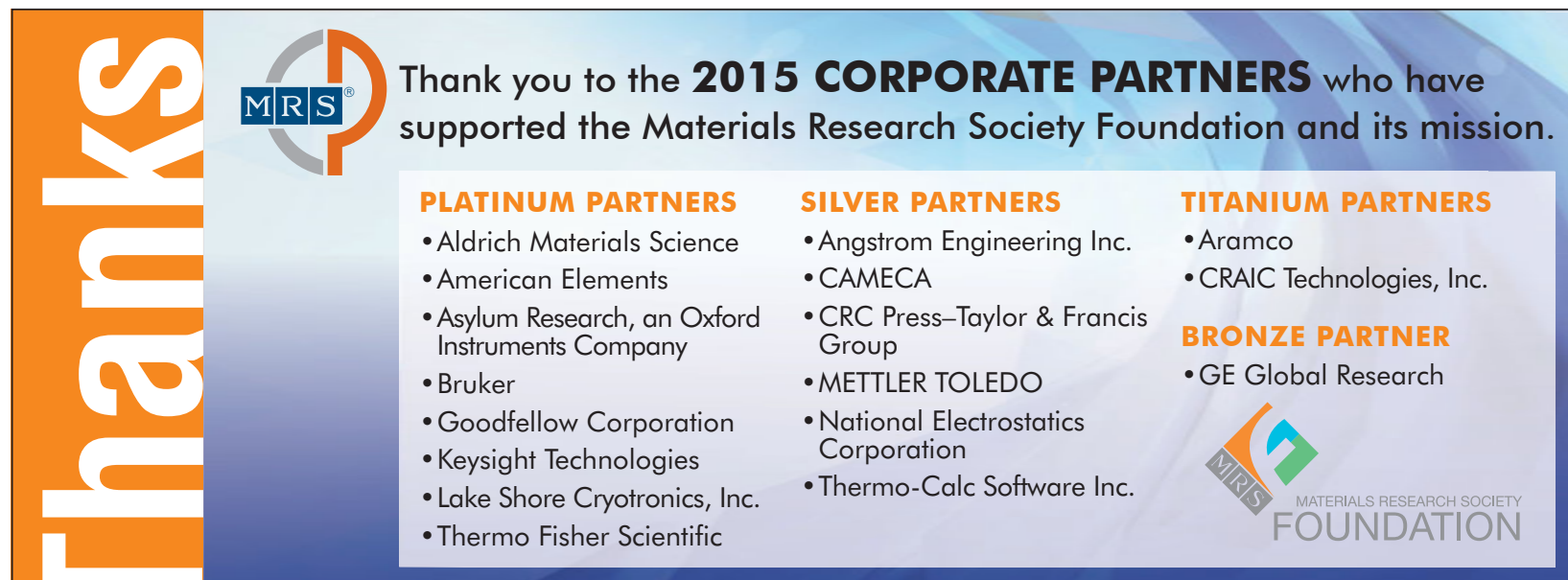

EVERY DONOR IS IMPORTANT. EVERY GIFT MAKES AN IMPACT.

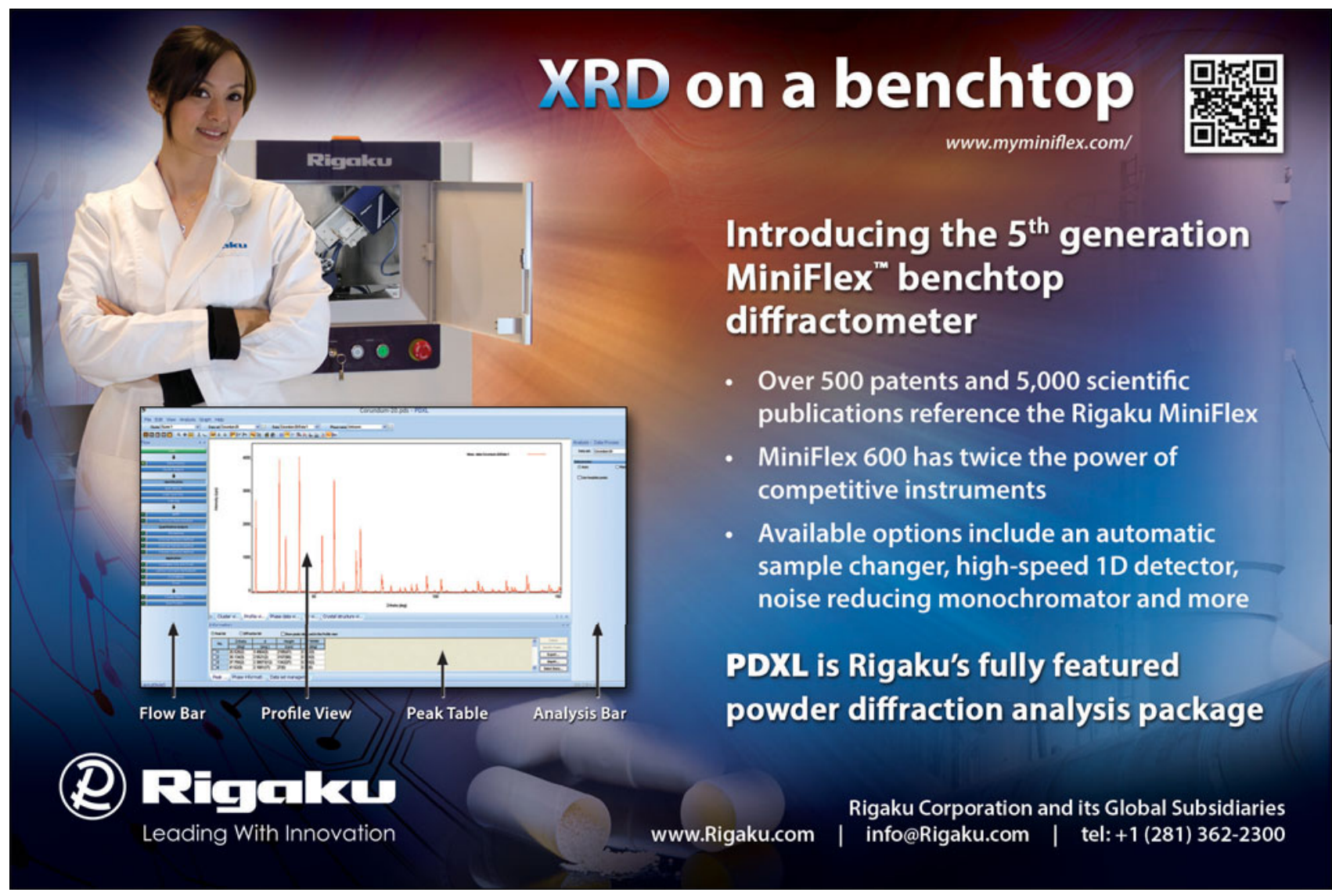




\section{SPECTROSCOPY OF IMIOBOSCOPL SAMPIES}

CRAIC Technologies ${ }^{\text {TM }}$ encourages you to discover how our advanced UV-visible-NIR microanalysis solutions can provide you with the tools and flexibility to take your research farther, faster.

- UV-visible-NIR range

Imaging \& Microspectroscopy

- Sub-micron sampling areas

Absorbance \& Reflectance

Raman \& Fluorescence

Small spot Film Thickness

- Polarization \& Colorimetry
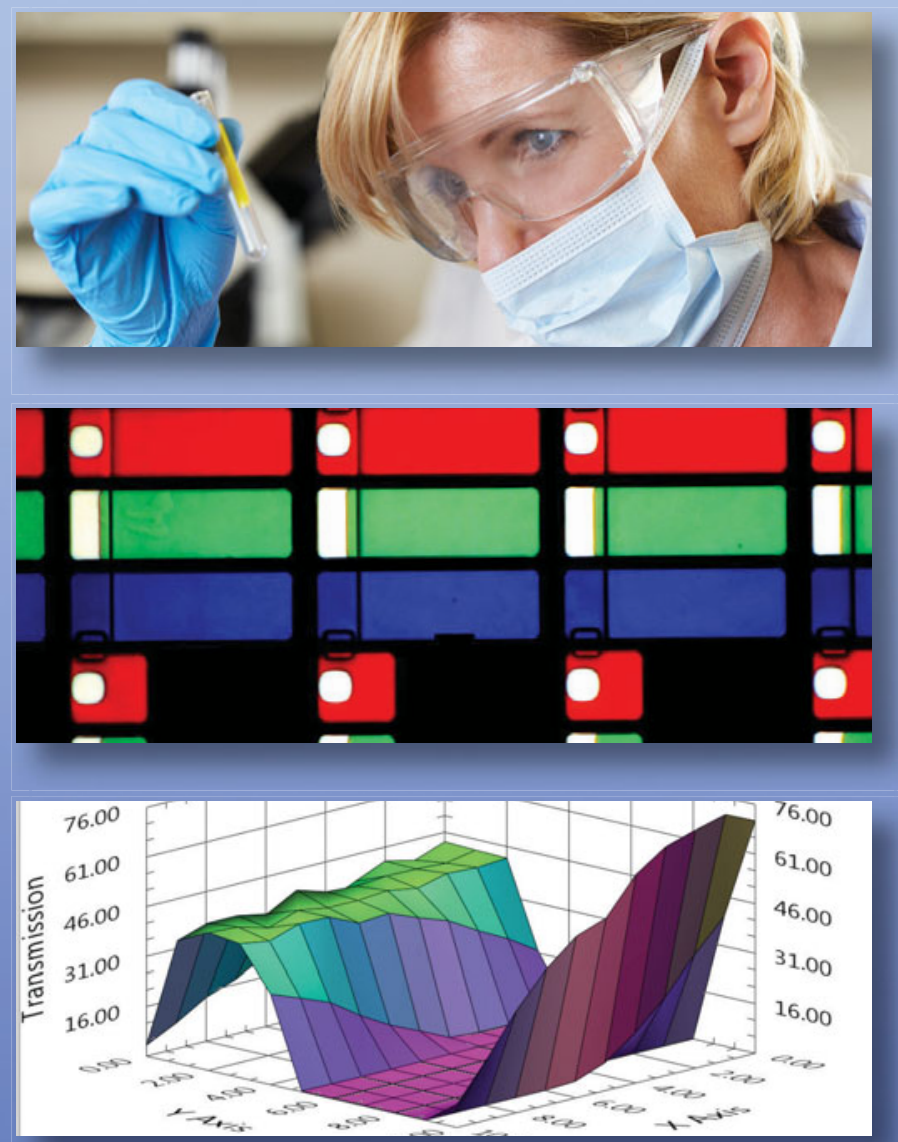

For more information, call 877.UV.CRAIC

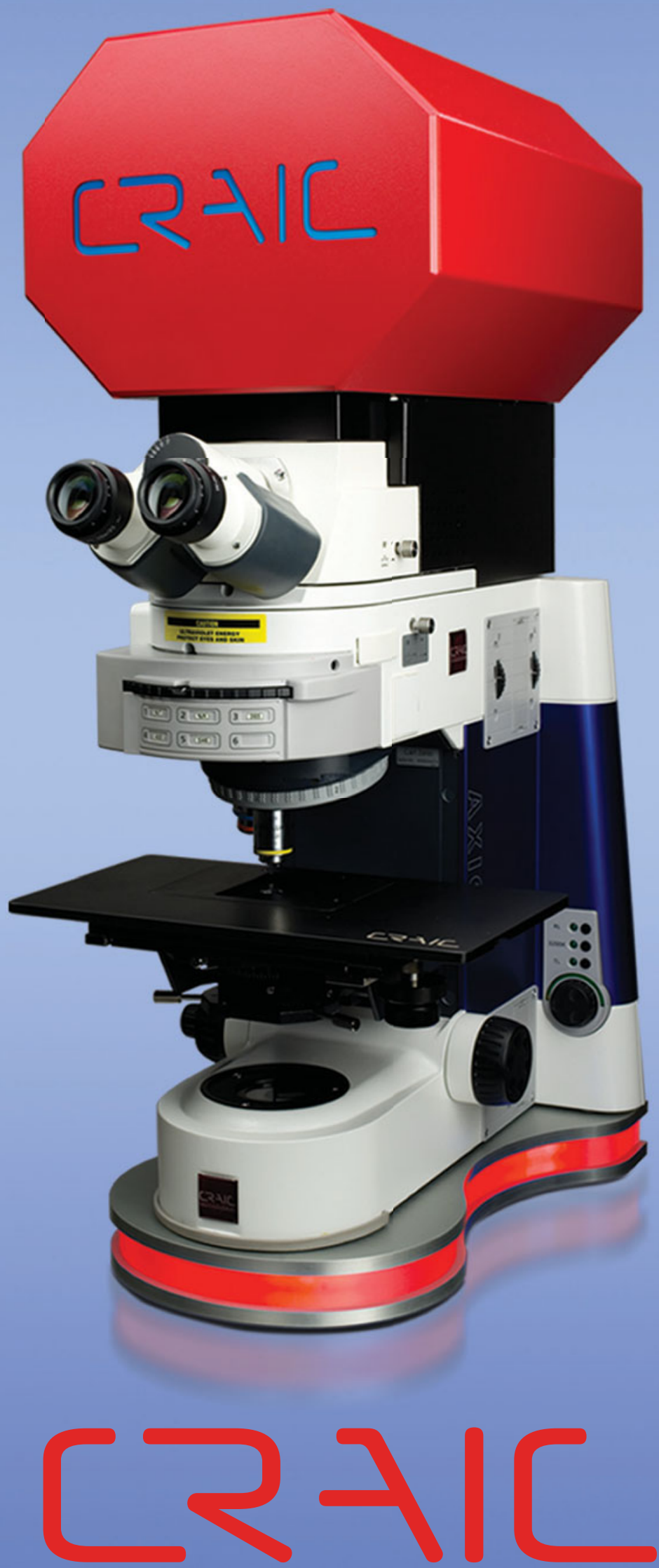

\section{TECHNOLOG I E S}

